\title{
Embryonic life and human life
}

\author{
M C Shea Freelance journalist
}

\section{Editor's note}

A new human life comes into being not when there is mere cellular life in a human embryo, but when the newly developing body organs and systems begin to function as a whole, the author argues. This is symmetrical with the death of an existing human life, which occurs when its organs and systems have permanently ceased to function as a whole. Thus a new human life cannot begin until the development of a functioning brain which has begun to co-ordinate and organise the activities of the body as a whole.

Although science has not established when a new human life begins, it has called into question the once 'obvious' answer, conception, by the discovery that twinning may occur up to fourteen days after fertilisation, and that occasionally the two zygotes thus formed may recombine into one. Scientists working on in vitro fertilisation (IVF) have found that the cells of the zygote can fall apart and sometimes have to be physically held together (1).

Even if, as many would say, the coming of a new human being is biologically a gradual process, it still remains true that at some point in this process the stage is reached where there can be no doubt that this new life is now fully human. A line still needs to be drawn somewhere.

An organism is an organised whole, the parts of which share a common life. An individual cell answers this description but it seems that the multiplying ball of cells of which the zygote consists does not. It is not yet an organised whole but a collection of individual organisms loosely held together by the jelly-like coating of the original ovum; a colony rather than an organism. Some of these cells will eventually form the placenta and others the embryo. In trying to establish when human life begins, therefore, the first answer which needs to be sought is, when do those cells which will form the embryo become an organism?

Life is not a state but an activity; the nature of the life of a living organism is indicated by the nature of its activity. If the life of the zygote - or rather, the life of

\section{Key words}

IVF; human life; reproductive techniques. its individual cells - is not yet human life, there ought to be evidence at some later stage of a change of nature from the not-yet-human to the human. That change $e_{\perp}$ would be evident in the becoming present of newi activities, or of new abilities giving the potentiality forc new activities: not a change of activity such that some을 ability already latent begins to show itself, but a changewhich indicates that new abilities and therefore new? potentialities have become present. The second answer to be sought, therefore, is whether at any stage in the 3 process of development there is any such evidence of a西 change of nature.

The commencement of cellular differentiation 950 evidence that the embryo has now become organise but there is no evidence from its activity to suggest thito the life of this new organism is human. Building thes new body by cellular replication according to genetico instructions interacting with environmental factors iső no more than the cellular activity which will continue@ to build and maintain and repair the body tissues for many years to come. It is not the activity we mean when 3 we speak of human life.

The nervous system begins to form early on duringo this process of embryonic activity; the brain develops from it, and seven or eight weeks after fertilisation the new heart is beating, the liver is at work and brain activity has begun. The basis of the various organs hasbeen laid, even though they are not yet fully developed, and in order to co-ordinate these new parts and systems a greater degree of organisation has become necessary. 옥

It is when this more complex organism begins to $>$ function as a whole that another level of activity appears, built upon the first: the reception and synthesising by the brain of neural impulses transmitting information from within the embryo'so own body and from its uterine surroundings, ancw activity which triggers off appropriate reactions for controlling the whole body's parts and systems as oneco This degree of organisation was neither needed at the beginning of the embryonic stage, nor was it possible until the neural system could function.

Without this new activity, not only could there be no? organisation as a whole of a body as complex as the? human one, but neither would there be any foundation for the more advanced activities of thought and reasoning which will commence when the brain which 
enables them has matured sufficiently in experience and structure. Experience in synthesising, beginning at the simplest level, is a necessary preparation of the brain for thought. Neural functioning both organises the new body and, as it grows more complex, will enable those mental activities which accord with our understanding of human life.

The evidence from organisation and from the commencement of new activities which give new abilities and potentialities, points to a change of nature when the new body begins to function as a whole, a change which enables the new organism to meet the criteria of human nature.

Further support for this thesis comes from the biological definition of a living organism: such an organism is cellular, can store and transmit information, reproduce itself, and is the product of an evolutionary process. The individual cells of the zygote answer this description, as do ova and sperm before fertilisation. But human beings - and blackbirds, dogs and chimpanzees come to that - fit the definition on two levels, the cellular and the holistic, and it is in every case only on the holistic level that the nature of the animal is evident. The countless billions of living cells of which our bodies are composed have the ability to reproduce themselves by division, and to store and pass on to each other the genetic information which comes to us from our ancestors, but at the same time on the holistic level we have the ability to reproduce sexually and to store and transmit information by memory and language, and this information is of an entirely different type. We - and blackbirds, dogs and chimpanzees - appear to have two levels of life. Death also comes on each level separately, suggesting that each level of life has its own distinct beginning.

Clearly the activity of our body cells is not what we understand as human activity. The nature of cellular life is not the nature of human life, even when those cells are working co-operatively as in the embryo. And equally clearly holistic functioning, with the complex human brain as the central information exchange point, enables human activities: life of an entirely different nature. Human life, it seems, is the activity of the functioning whole.

Similarly, chimpanzee life is the functioning of the whole chimpanzee, but its activities reflect the capacity of the chimpanzee brain and body structure. Biochemically the human embryo differs from the chimp embryo just as the chimp embryo differs biochemically from the canine embryo. The embryonic cells of a dog cannot build the wings of a bird and neither can those of a chimpanzee build a human body, therefore holistic functioning in any one species means the beginning of life of a new individual member of that species. Biochemistry makes vitalistic belief in a 'life force' obsolete: the nature of life differs according to the biochemistry of the species. Only human genes can build a functioning human organism and thereby enable the commencement of human life.

Meiosis - the formation of the sex cells - fertilisation and implantation in the uterus are all cellular processes with no change of activity such as would suggest a change of nature. But holistic functioning with transmission and organisation of information other than genetic is undeniably a new activity and one which, together with the reproductive ability which the sexual organs give, fulfills on a second level the biological definition of life. There is every indication that here is the beginning of a new and more complex nature.

This argument lends support to the idea that just as permanent cessation of all relevant activity (in Britain brain stem activity) in the human brain signals the end of human life - when life support machines, if in use, may be switched off - so the beginning of such activity signals the beginning of a new human life, but there is a distinction: this activity must be the necessary precondition before the whole can begin to function; the neurons must need to become active within the brain before they can start co-ordinating the working of the whole body. The transmission of information other than genetic may have commenced, but as central nervous system neurons, unlike the other body cells, cannot reproduce themselves, this is not yet a new level of life. Detection of brain activity would indicate that the second level of life will soon - very soon, given the speed the embryo develops commence, and therefore could be taken to herald the beginning of a new human life, and similarly at the end of life permanent cessation of brain activity confirms that the whole has ceased to function.

An objection often raised against brain activity criteria and which could also be turned against this functioning-of-the-whole theory is that the beginning of a life cannot be compared with the end. That there can be no comparison does not, however, make the criteria wrong; what it does is to say that that which exists after functioning ceases is not the same as that which exists before functioning begins. After the cessation of the functioning of the whole, that which exists (although not for long unless artificially supported) is human cellular life no longer capable of maintaining the individual holistic life which is human life. Before functioning begins in the embryo that which exists is human cellular life in the process of building up to the individual holistic life which is human life. It is this difference which ethical decisions need to take into account.

After a certain degree of complexity has been reached in the embryo cellular life can continue only if the parts of this complexity begin to function together, but this holistic level can continue only so long as the cellular level continues to maintain its parts. The two levels of life become dependent upon each other.

For the whole to function as one organism there needs to be sufficient brain activity to regulate and coordinate the workings of the various body organs and systems. Sometimes the activity of the human brain is impaired by disease or accident or some genetic 
malformation, but so long as there is sufficient activity to maintain some degree of holistic life - that is, to keep the nervous system working as an integrated unit regulating essential systems such as the cardiovascular (and if there were not, life could not continue even at cellular level) - then that life is human. That is to say, the quality of the functioning of the various organs is not the criterion of human-ness. An individual who is mentally defective, whether from birth or accident or old age, is fully human, just as is one whose eyes or legs are defective. If all holistic activity were absent life at the cellular level could not be maintained; if any holistic activity is present in a body which is genetically human, no matter how defective parts of it may be, it is human life.

Where artificial life support is given, it would seem that the patient is living only because machines are enabling the maintenance of the second level of life, and this enables cellular life to continue. So long as there remains the relevant activity in the brain it seems there is the possibility that the natural functioning of the body as a whole may be resumed if the failed essential parts of it recover sufficiently or are replaced.

It has been objected that to distinguish between biological life and life where human characteristics are observable is philosophically untenable because it is all the life of one, unique, individual organism which is passing through various stages of growth, and that because each stage in the development of a new individual is the necessary condition for the following stage no moment can be distinguished as more decisive than another. Granted that, at least from the time of implantation or thereabouts, there is an individual organism, if that organism changes both the nature of its organisation as a consequence of greater complexity, and the nature of its activity, then the two levels of life can logically be distinguished. Evolution has always included building up upon what went before: it is in this way that the more complex has come from the less complex, and with greater complexity new properties emerge, and with new properties a new nature.

Although the theory put forward here was developed from an evolutionary basis it nevertheless seems to present no contradiction even to Aristotelian or Thomist philosophy because a being with two levels of life, one built upon the other, and two levels of activity, one cellular and the other holistic, may reasonably be thought to have a different 'essential form' or organising principle from one with only one level of life and one level of activity. The theory does not, however, depend upon any particular understanding of how it is that bodies become organised.

The nature of the fetus is observably sufficiently different from that of the embryo to make it evident that a change of nature has occurred. If that is so the embryo cannot be a full human being: its life is not human life. On the other hand, as nothing seems to occur after the end of the embryonic stage which could be used as evidence to suggest that there has been another change of nature, it can only be concluded that the change at that stage is the begining of a new human nature; that a fetus is a full human being.

With the commencement of the second level of life $\stackrel{\overrightarrow{\vec{D}}}{\stackrel{\vec{D}}{+}}$ all the particular characteristics of a species become $\bar{c}$ fully potential. Although manifestations of human life, 음 such as bipedal walking, self-consciousness, reasoning $\frac{\omega}{-}$ ability, moral sense and personality, come later, they $\propto$ develop from and are enabled by this basic holistic $\%$ activity. Everything required for their establishment is $\vec{\circ}$ fully present: the organs are present and the functioning which will develop them has begun.

'Quickening' cannot be an indication of a change of nature because ultrasound screening now shows the fetus moving about many weeks before it can be felt by its mother, in fact very soon after the commencement $\vec{A}$ of holistic functioning, and this functioning may reasonably be presumed to enable movement to begin. O

The fact that medical science has been pushing back 으 the age at which premature infants can survive makes it obvious that it is the improvement in the environment, not any change in the nature of the infant, which affects viability. Birth at full term is also a traumatic change of environment, but a change of $\underset{\Phi}{\sigma}$ environment does not change the nature of that which goes through the experience, however traumatic.

It is likely that personhood builds up from the tinge on when the nervous system starts sending the braig information from its uterine surroundings, because prenatal mental experiences, even though unconscious or subconscious, presumably influence brain structure

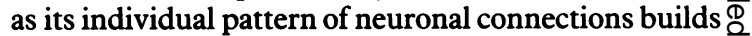
up and the cerebral cortex matures, and this in turn $\vec{F}$ may well influence the kind of person this will be, as $\frac{}{3}$ also may the quality of maternal bonding even before $?$ birth. Person and psyche are in that case already? forming during the fetal period, their development enabled and influenced by neural functioning, and $\bar{\Phi}$ consciousness similarly develops gradually as neural 0 functioning grows more complex. There is no evidence of the later addition of something new, personhood, 8 which was not already potential at the very begininng of the fetal stage and capable of development from? what was then in existence, and therefore no evidence $\square$ for a change of nature later than that time.

The nature of the newborn baby appears to be then same as that of the earliest fetus in that he has the same two levels of life, the same organs and systems, the $N$ same potentialities, and that which is functioning as a whole is the same collection of parts. There has been noO addition to these, no third level of life has appeared, noo new organs; only growth and development of what existed then. Throughout the whole process from? meiosis to birth and beyond, the commencement of the 7 functioning as a whole of the newly-formed body seems? to be the only event which can claim to bring about a clear change of nature in that it makes of the parts $a_{\propto}^{\mathbb{\Phi}}$ new organism, it establishes a new level of life, and ito brings new abilities and potentialities which were not 
present earlier and to which nothing is added later. The necessary and sufficient criteria for a new human life are fulfilled at that commencement.

Nevertheless the human embryo, and even the zygote, cannot be dismissed as 'nothing but' human cellular material comparable with human blood or skin cells, or even a malignant growth, firstly because it is by nature a human embryo with human genetic potential - that is the potentiality for building a new and unique human organism - and secondly because fertilisation of the ovum can make a particular claim unlike that of any other event. All other processes are carried out by the body cells according to the genetic instructions they carry and their environmental promptings: meiosis happens 'automatically', so does the development of the fertilised ovum and implantation of the resultant ball of cells in the uterus; so does the formation of the embryo and the commencement of heart and liver and brain activities, and the development of the fetus and the birth of the baby. But fertilisation of the ovum by the sperm cell cannot happen of its own accord. A new human life is not the automatic product of cellular life. Fertilisation can take place only by the intrusion of human holistic life. Sperm and ova must be brought together either by sexual intercourse or by laboratory procedures, and only then can the sex cells, if conditions are right for them, unite and begin the processes which build a new human body.

This could, of course, be said of many species of animal, but there is a distinction on the human level in that animal sexual behaviour is genetically dictated even though a holistic action: biochemistry sees to it (barring accidents outside its control) that male and female mate and in some species may even dictate which individuals shall mate (the strongest male, for example), whereas adult human beings are capable (or should be!) of overriding, or guiding the use of, biological urges and freely choosing whether or not to have intercourse, or when and with whom to have it. Human intelligence, moral sense, freedom from genetic dictation and ability to choose whether to create a new human life within a loving relationship or with careless irresponsibility, are new factors not present in other species, and are an aspect of the fully developed human whole which necessarily enters into the bringing into being of the human embryo and makes it far more than an automatic creation of biochemistry.

Consequently, although the fertilised human ovum may not yet be a human being as such because it lacks the second level of life of full humanity, it nevertheless owes its existence to the holistic as well as the cellular life of its parents. It is a product of human responsibility. Even where conception was not wanted it makes no difference to the zygote itself because it still remains that it exists only because of an action on the second, fully human level, and this, together with its genetic individuality, puts it in a 'transitional' state. It is not the equivalent of other body cells.
With the commencement of cellular differentiation a considerable advance has been made in this transitional state, for differentiation suggests that the embryo has now become organised as a new individual being even though the organisation cannot yet be of the sophistication which will later be necessary, and even though life is present on one level only. By the end of the embryonic stage the period of transition is complete and life of a new nature begins: the life of the functioning whole.

\section{Ethical implications}

If the foregoing were granted and if in our ethics we take as a general guide 'love your neighbour as yourself', it could be concluded that as the life of the embryo is not yet human life there is no need to extend our neighbourly love to it in the form of care and protection. The way would therefore be open for using 'spare' IVF embryos (including in the term the early stages after fertilisation) for medical purposes. Nevertheless there remains cause for hesitation because this treats the embryo as if it were nothing more than a hair or a drop of blood, and also sets no bounds to its use.

To take the opposite stand, however, and decide it is better to be on the safe side and ban all use of surplus embryos, or ban IVF altogether if necessary in order to avoid the problem, also gives cause for hesitation, for if by medical use of embryos cures might be found for genetic diseases and drugs tested for safety, to name some possibilities, and if there is no other way of carrying out such work, then to ban it is not an ethically 'safe' escape route but is a decision not to use available means to relieve human suffering.

The 'transitional' status of the embryo points to a way out of this dilemma, the third choice: to extend care and protection to embryonic life unless this conflicts with the good of fully human life - to treat the embryo as our neighbour calling for our love so long as answering its call does not deny the love due to those who are more fully our neighbours.

This not only gives the embryo its due transitional dignity but also, in the case of IVF embryos, provides a measure for setting the bounds to its use: if in recognition of its near humanity love is extended to the embryo unless overruled by love for the fully human, then it follows that the embryo could be fittingly - that is without diminishing its own proper value - used for the relief of human suffering even if it does not itself benefit, but that it would not be fitting to use it for any reason less than relieving or preventing that human suffering which cannot be efficiently relieved or prevented in any other way.

Similarly, selection or rejection of IVF embryos for return to their mothers would be limited, by this measure, to that which is essential for the elimination or prevention of human diseases: the door to selection on the ground of preferred sex (except in the case of sex-related genetic diseases) or hair colour or particular 
talents would not be opened because such would not be consistent with the love due to the embryo, nor uphold its proper dignity.

Exercising even this limited selection by means of abortion either of an IVF embryo which has been returned to its mother, or of an embryo conceived in the normal manner, is a far weightier matter. Terminating the life of an embryo which is in utero cannot be compared with denying the chance of life to an embryo in the laboratory. The embryo already in its natural environment has every chance of surviving unless steps are taken to prevent it, whereas the one in the laboratory has no chance of surviving and developing unless steps are taken to give it the necessary means. For the first, death comes from being deprived of something it already has, at least if it has become implanted in the uterine wall, when all that is necessary for a new individual human life to develop has been completed. For the second, death comes from not being given something it lacks - the human work of assisting nature to create has not yet been completed.

Moreover, if an IVF embryo is surplus to requirements, then the means for its continued survival and development - presuming that gestation by its own mother are the appropriate means - are not available and its destruction therefore does not deny life to any human being who might otherwise have come into existence. This cannot be said of the embryo in utero.

If due regard is given to the embryo's transitional, near-human status, a decision to abort would be unjust, and therefore unethical, unless all relevant facts were weighed. Prenatal diagnosis of embryonic abnormality cannot often predict the degree of abnormality of the baby at birth and therefore it would seem ethically the better course to wait until birth and then make a 'live or let die' decision on its actual condition. To give the embryo a chance would also seem more in keeping with the 'neighbourly love' which ought if possible to be extended to it. The fact that a negative decision is easier to make when the patient cannot yet be seen is not an ethical reason for making it at that time.

The argument presented above, that a new human life begins when the newly built body organs and systems begin to function as a whole, and that zygote and embryo are in transitional states, seems to suggest that limited medical use of surplus IVF embryos is ethical - even that failure to take this opportunity to relieve human suffering would be unethical - and the Warnock Committee's recommended time limit of 14 days is reasonable, but that abortion is ethically dubious even before the beginnng of the fetal stage.

MC Shea is a freelance journalist and the author of an as yet unpublished book, The Human Challenge. Her address is 58 Woodland Avenue, Woodley, Reading.

\section{References}

(1) Roberts P. The Brennan story: a small miracle of creation. In: Walters W, Singer P, eds. Test tube babies. Melbourne: Oxford University Press, 1982: 17. 